\section{RECENT DISCOVERY OF PIT-DWELLINGS}

URING the late summer, while engaged in excavating a Roman building at Finkley, near Andover, a deep trench, Ioo feet in length, was found, dilating at the opposite ends into large subterranean pits, which, from the primitive character of the articles met with in them, such as flint and bone implements, spindle-whorls of chalk, and a rude form of pottery, appeared to belong to an earlier period than the Roman. One of the labourers engaged in the explorations became quite an expert in the recognition of these rude objects; and he having lately been employed in digging a yard at a new railway station, situated on a hill, about half a mile distant from St. Mary Bourne, immediately overlooking the Upper Test Valley, found the subsoil so abundant in calcined stones, broken pottery, and other evidences of early occupation, that he called my attention to the circumstance, which led to the discovery of a group of pit-dwellings or hut-circles; and it is likely, from their mode of arrangement, that they form a portion of an extensive settlement or vicus. Some knowledge of nine of these has been obtained, although, from their situation, two only have been completely investigated, and five others partially.

The pits occupy the space of about a quarter of an acre, and have all entrance shafts, sloping gradually downwards from their inlets, and widening as they approach the pits. They may, with their contents, be described seriatim. No. I is oval or pear-shaped, having its entrance southwards. Its length is 22 feet from the end of the pit to the mouth of the alley; greatest diameter 12 feet; depth at the centre of the pit 5 feet. This was the only circle that contained flints, of which twelve cartloads were removed from it; and as some of the stones were arranged in courses, without mortar, around its circumference and on each side of the alley, I have thought that the superstructure must have been of flint, and had fallen in. The relics found were chiefly at the centre, where the fire-place had evidently been; the smoke most likely escaping through the centre of the roof. They consisted of about a bushel of calcined flints, bones of a small species of Bns, probably longifrons, Cervus elephus, Capra, Sus, and Canis, besides broken vessels, chiefly of a very rude, hand-made kind, although a few pieces found about the pits bore wheel-marks. The bones had mostly been split open in order to obtain their marrow. They had further been exposed to fire, and bear impressions made by teeth and knives; and some of the smaller long bones had evidently been used as marrow-spoons, while other small splinters of bone had the appearance of having served the purpose of awls or needles. In this circle also part of a rude sandstone hand grain-rubber was found, besides some flint-flakes, a scraper, and some cores ; and, in addition, the outer lip of a large cowry, which had been carefully cut from the shell, and had been used as a rasp, the crenulations in the lip being considerably worn down. It had further been employed as a polisher apparently, the enamel being worn away in places.

Pits 2 and 3 were only partially explored, as they extended beneath the station yard. One of them, however was partly filled with calcined flints; and in it were found a piece of a grain-rubber and pottery and bones similar to those just described.

Pits 4 and 5 had only portions of their passages opened, as the pits extended beneath the Station Road. In these we found a few flint-flakes, and some calcined stones.

Pit 6 contained no remains, as it was evidently the passage only of a pit partly formed, and had not been occupied.

In digging a well in the station garden similar relics were thrown out, and it is evident that the shaft of the well passed through one of these pits ; and, as additional evidence of British occupation, in clearing away the soil around the circles, one of the labourers picked up a Gaulish gold coin, which bears on its obverse and reverse degraded representations of more perfect figures. The coin, in short, is a slightly more perfect copy of the lowermost of the three coins depicted at p. 84 of "The Celt, the Roman, and the Saxon," Ist. ed. ; which figure is there stated as being a rude copy of a gold stater of Philip of Macedon.

Pit 7 was fully explored. It was $42 \mathrm{ft}$. in length from the extremity of the pit to the mouth of the passage, which opened eastward; its widest diameter $13 \mathrm{ft} .6$ in., and depth $5 \mathrm{ft}$. at the pit's centre. Here the fire-place had stood, as in No. I, and around it we found bones similar to those discovered in Pit $\mathrm{I}$, with the addition of some teeth of a small species of horse, and bones of the hare or rabbit. The bones were, in most cases, broken, and some of them had been wrought for use as implements. Two flint arrow-heads were found in the alley, and the centre of the circle further contained flint-flakes, scrapers, cores, and arrow-heads, a fragment of a rude grain-rubber, and a flint muller showing use on one side. Here also occurred a whetstone, made from a piece of sandstone such as I have observed occurring in the drift of the Reading beds; and evidently from the same drift a lump of native ironstone, containing a large percentage of iron, which had been picked up by some occupant of the pit and used as a hammer. As throwing:some small light on their domestic economy, a chalk spindle-whorl was found, and with it a small disc of pottery, bored at the centre, the direction of the hole showing that it had been suspended by a string, perhaps round its owner's neck. The whole of the fictile ware found here was of a rude hand-made type, and some of the "crocks" were scored with irregular zigzag lines, made appareritly with a pointed stick.

At nine feet south of Pit 7 a circular hole in the chalk was cleared out. It was found to be $5 \mathrm{ft}$. in diameter and $3 \mathrm{ft}$. in depth. It contained a quantity of bones of animals similar to those already enumerated, with snail shells that had been exposed to fire; and beneath the bones a number of charred flints, with charcoal and ashes. It was evident that strong fire had been employed here, as the chalk was in places burnt through and discoloured to the depth of several inches, which led to the inference, coupled with its contiguity to Pit 7 , that it was a cooking-hole. It is not unusual for uncivilised people, as the negroes, to have their cooking places outside their dwellings (see "Flint Chips," by E. T. Stevens, p. 59).

At another part of the same yard, about Io ft. of wellbuilt wall was removed. It was doubtless Roman, as near it a better kind of pottery was found, including a piece of Samian, besides two roof-nails and a bronze buckle.

The quantity of calcined stones everywhere present was the most striking feature in the remains. Some of them, I observed, were faced on one side, and a few had facets at right angles, and these, it occurred to me, might have been used in constructing ovens or fire-places. A large number, however, were perfectly circular, and had bright, clean surfaces ; these might have been employed for the purpose of stone-boiling.

With traces of Roman occupation we have here these rude remains which slow residence by an earlier people, who, doubtless, lived on after the advent of the Romans. I have, as yet, observed no entrenchments in the field; but there is no doubt that similar circles occupy a large space of the upper slope of the valley. The flint implements stamp the remains as Neolithic; and those found in the pits differ in no respect from the wrought flints occupying the subsoil of the yard, as well as occasionally occurring on the surface of the adjoining fields. The settlement is favourably situated to have enabled the occupants to obtain water from the river Test; and along the same side of the valley, within the space of two miles, I have discovered more than one working site, in which I have obtained a large and varied collection of tools and weapons both chipped and polished. 
These huts must have been covered, some, perhaps, with stones, others with a wooden or wattle superstructure, covered with clay or sods of turf; and their poor inhabitants evidently cultivated, to a small extent, some of the cereals, had an early knowledge of weaving, and lived domesticated with oxen, goats, and swine. The red-deer were most likely obtained by hunting in the dense forest that then occupied the deep clay lands of North Hampshire, as an extension of the ancient forests of Harewood, and Chute, and Finkley. Further, these shallow pits might have been the summer residences of a people whose winter habitations were at Finkley.

\section{J. STEVENS}

\section{INAUGURATION OF THE OBSERVATORY AT CORDOBA}

$A \mathrm{~N}$ interesting account of the inauguration of the A Argentine Observatory at Cordoba in October last appears in the Standard of Buenos Ayres. The chief feature of the ceremonial was a very able address by Prof. Gould, the Director, from which we make the following extracts, as bearing specially on the work of the observatory :-

"In the year $175 \mathrm{I}$ a French astronomer, the Abbe de la Caille, visited the Cape of Good Hope for the purpose of determining the positions of the principal southern stars. With a little telescope of comparatively insignificant dimensions, he succeeded in obtaining the materials for so complete a catalogue-as far as the limit of brightness which his telescope permitted-and in determining the positions of those stars so well, that this catalogue of about 9,800 stars constitutes to-day the chief reliance of astronomers for their knowledge of a large portion of the southern sky. Since that time a permanent observatory has been established by the British Government at the same place, and a large number of valuable observations have been made by various eminent men. Other observatories in the southern hemisphere have been founded at Paramatta, Santiage de Chile, and Melbourne, all of which have contributed essentially to our knowledge of the southern sky; as also has the observatory at Madras, which, although north of the equator, commands a view of the greater portion of the southern heavens. Yet how much remains to be done in this direction will be very evident when I state that, while the number of stars in the northern hemisphere whose positions and magnitudes have been determined cannot fall short of about 330,000 , the number in the southern hemisphere whose observed places have been published does not probably exceed 50,00\%. But this is not all. The greater portion of those which have been observed lie in that part of the sky which is clearly visible in Europe; and if we consider the regions beyond $30^{\circ}$, there are scarcely i 3,000 southern stars whose places and magnitudes have been determined and made available for scientific use, while the corresponding portion of the northern sky contains something like 164,000 such stars.

"The first undertaking now proposed for the Argentine Observatory is to do something towards filling this hiatus by determining the places of the principal stars situated between the tropics, where the observations of northern astronomers begin to become less numerous, and the polar circle, where Gilliss' observations commence. This work is best performed by dividing the sky into narrow zones or belts, and subjecting each zone to a special scrutiny for the purpose of measuring the positions of all stars of a sufficient brightness within its limits. If no unforeseen impediment presents itself, these observations should be completed within two years from their commencement.

"There is another most important investigation especially desirable in the present condition of our knowledge : this is the application of the newly-discovered methods of stellar photography to the more prominent objects in the southern heavens. The ingenious researches and inventions of $\mathrm{Mr}$. Rutherford in New York have resulted in the development of methods by which the relative positions of clusters of stars may be permanently recorded by photographing them upon glass, and the numerical values subsequently determined by means of a measurement of the photographic impressions, with a degree of precision far greater than that of the ordinary methods. And this process possesses the signal and peculiar advantage, that the representations thus obtained of the stars' places at a given moment may be preserved, and the measurements repeated at any subsequent time. The process has not yet been introduced into European observatories, but it has been thoroughly tested in America, and valuable researches have already been made by this photographic method.

"During the greater part of the year we have had neither instruments nor building, and during the short time these have been available we have experienced an unexpected and most serious obstacle in the clouds of impalpable dust, which, rising from all sides, penetrate to the inmost crevices of every part of the instruments. This difficulty will, I think, be obviated to a great extent when vegetable growth shall have covered the soil ; and to this end the Minister has given directions for providing as good a supply of water as may be possible, while the building and instruments have been provided with special and unusual protections against the evil. The position of the city of Cordoba renders this trouble inevitable, inas. much as water for irrigation is only to be found in the valley, whilst an observatory must necessarily be placed upon high land. With the arrival of the rainy season I trust that a carpet of vegetation may remove this source of anxiety.

"A considerable time would, under any circumstances, have been requisite for computing the numerical table, and making the various other calculations needful for bringing the instruments into active service. The additional interval has been employed in an undertaking of a totally different sort, which may, I trust, be found in the end to possess as much scientific importance as the work originally intended. During this period of enforced delay we have succeeded in making a full catalogue of all those stars of the southern heavens which are visible to the naked eye, determinirig for each one the precise degree of its brightness. When, after the moon has set to-night, you raise your vision to the starry sky, and, as you look more intently, perceive one faint star after another reveal itself to your sight, you will yet succeed in discerning no star whose place and magnitude has not been recorded within the past year by some one or more of the observers in this institution-

$$
\text { " 'Sidera cuncta notans tacito labentia cœls.' }
$$

"The progress of the work so far has not failed to afford its due share of discoveries. It has given us the knowledge of a considerable number of stars which possess the singular character that their brightness is not always the same, but undergoes systematic variations. Some have been seen to rise to considerable brilliancy, and then fade away until telescopes of some power are needed for rendering them visible. Others still are now found to possess a brilliancy decidedly greater or decidedly less than that which has been assigned to them by more than one astronomer in times past. Such stars must be carefully watched, and the fact of any regular and periodic fluctuation in the amount of their light either established or disproved. Of such cases there are already many on our records, thanks to the assiduity and zeal of the assistant astronomers, no one of whom has failed to make manifest the existence of several. One of those most remarkable for the rapidity of its changes is a little star in the constellation "Musea," which is invisible to the unaided 